\title{
COMPARATIVE STUDY OF EXTRACRANIAL CAROTID AND VERTEBRAL ARTERY DOPPLER WITH CONTRAST ENHANCED MR ANGIOGRAPHY IN PATIENTS WITH STROKE
}

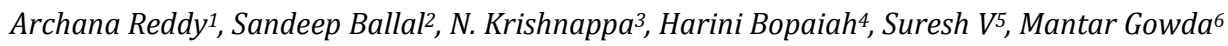 \\ ${ }^{1}$ Resident, Department of Radiodiagnosis, Kempegowda Institute of Medical Sciences, Bangalore. \\ ${ }^{2}$ Associate Professor, Department of Radiodiagnosis, Kempegowda Institute of Medial Sciences, Bangalore. \\ ${ }^{3}$ Professor, Department of Radiodiagnosis, Kempegowda Institute of Medical Sciences, Bangalore. \\ ${ }^{4}$ Assistant Professor, Department of Radiodiagnosis, Kempegowda Institute of Medical Sciences, Bangalore. \\ ${ }^{5}$ Associate Professor, Department of Radiodiagnosis, Kempegowda Institute of Medical Sciences, Bangalore. \\ ${ }^{6}$ Assistant Professor, Department of Radiodiagnosis, Kempegowda Institute of Medical Sciences, Bangalore.
}

\begin{abstract}
CONTEXT

Cerebrovascular accident or stroke is one of the most common causes of death. Ultrasonography of the carotid arteries is an easily available, cost effective, non-invasive method of evaluation. Treatment of stroke depends on reaching the most accurate diagnosis. Accurate and prompt diagnosis is crucial because timely and appropriate therapy can significantly reduce the risk of stroke and long-term sequelae. Several modalities of investigation are available to determine carotid artery status. The value of safe, noninvasive screening test is therefore great.
\end{abstract}

\section{AIMS}

The purpose of this study is to compare the diagnostic value of extracranial carotid and vertebral artery Doppler and Magnetic Resonance Angiography for the diagnosis of carotid artery pathology in patients with stroke.

\section{SETTINGS AND DESIGN}

The principal appealing points in favour of sonography are patient comfort, accuracy and lack of risk. MR Angiography produces reproducible three dimensional image of carotid bifurcation with good sensitivity for high-grade stenosis.

\section{METHODS AND MATERIAL}

After taking consent, 50 patients presenting with focal neurological deficit underwent Colour Doppler and Gadolinium enhanced MRA examination of the carotid and vertebral arteries at KIMS Hospital, Bangalore, with the help of VOLUSON 730 [WIPRO GE ULTRASOUND MACHINE] and GE SIGNA HDXT 1.5 TESLA 16 CHANNEL MRI.

\section{RESULTS}

The highest incidence of stroke was found in the age group of 50-70 years with male population commonly affected. The various risk factors include family history of stroke, hypertension and diabetes mellitus. Total pathologies were most commonly found on the right side. Most common site for atheromatous plaque was carotid bifurcation. Grading of stenosis was done based on the NASCET criteria and the findings of Doppler and MRA were compared. MRA had a better role than Doppler for detecting $80-99 \%$ stenosis.

\section{CONCLUSIONS}

MRA has progressively gained clinical relevance in the evaluation of the cerebrovascular disease and has become a powerful tool for accurate and early diagnosis of causes of cerebral ischemia. It has better discriminatory power compared with Doppler in detecting $80-99 \%$ stenosis. The length of the occlusion, collaterals and distal intracranial segment morphology can be better assessed by MRA and this method is not operator dependent.

Colour Doppler examination is a non-invasive, economic, safe, reproducible and less time consuming method of demonstrating the cause of cerebrovascular insufficiency in the extracranial carotid artery system and will guide in instituting the treatment. Doppler has a better role in the evaluation of the morphology of the stenosis particularly plaque morphology and estimating the degree of stenosis.

\section{KEYWORDS}

Colour Doppler; MRA; Stenosis; Stroke.

HOW TO CITE THIS ARTICLE: Reddy A, Ballal S, Krishnappa N, et al. Comparative study of extracranial carotid and vertebral artery doppler with contrast enhanced MR angiography in patients with stroke. J Evolution Med Dent Sci 2016;5(3):189-195,

DOI: $10.14260 /$ jemds/2016/43

Financial or Other, Competing Interest: None.

Submission 26-11-2015, Peer Review 27-11-2015,

Acceptance 11-12-2015, Published 09-01-2016.

Corresponding Author:

Dr. Sandeep Ballal,

B-001, Adarsh Esplanade, HSR Layout,

Sector-7, Bangalore-560102.

E-mail: s_ballal@yahoo.com

DOI:10.14260/jemds/2016/43

\begin{abstract}
INTRODUCTION
Stroke is a life-threatening and debilitating neurological disease. It is the third leading cause of death in the world. Ultrasound of the carotid arteries is the modality of choice for the triage, diagnosis and monitoring of the cases of atheromatous diseases. There are several pitfalls that may mislead the operator to falsely interpret the colour and spectral Doppler findings. Several modalities of investigation are available to determine the carotid artery status.
\end{abstract}


The value of safe, non-invasive screening test is therefore great. The purpose of this study is to compare the diagnostic value of extracranial carotid and vertebral artery Doppler and Magnetic Resonance Angiography for the diagnosis of carotid artery pathology in patients with stroke. Colour Doppler sonography became a mainstay in the evaluation of the extracranial territory and its accuracy in comparison with MRA is well established. Carotid sonography has largely replaced angiography for suspected extra-cranial carotid atherosclerosis. ${ }^{1}$

The principal appealing points in favour of sonography are patient comfort, accuracy and lack of risk. In contrast, the Digital Subtraction Angiography is invasive and expensive. Moreover contrast related adverse effects also contribute to significant morbidity. In symptomatic patients like those with hemispheric symptoms or TIA, carotid ultrasound may be the only diagnostic imaging modality performed before carotid Endarterectomy. ${ }^{2}$

Besides estimating the degree of stenosis, the biggest advantage of sonography is its ability to identify and characterize plaque and identify plaques with higher risk of embolization with the use of high resolution ultrasound. Plaque can be characterized into relatively high risk groups for containing intra-plaque hemorrhage which is thought by many to be the precursor of plaque ulceration. ${ }^{3}$ MR Angiography produces reproducible three dimensional image of carotid bifurcation with good sensitivity for high-grade stenosis. The advantage is that, the more distal internal carotid artery, aortic arch and proximal great vessels, Circle of Willis, and the vertebrobasilar system can all be assessed and the method is not operator dependent. Preoperative assessment of the carotid bifurcation by MRA and duplex sonography can replace Digital Subtraction Angiography.

\section{SUBJECTS AND METHODS}

This study was carried out in patients who had symptoms and signs of strokes or transient ischemic attacks at Kempegowda Institute of Medical Sciences, Bangalore, from the period of November 2011 to September 2013.

The study was carried out on 50 patients. A detailed clinical history was taken and clinical examination findings were recorded. Risk factors like hypertension, diabetes mellitus, smoking and ischemic heart disease were documented.

The data gathered from the Colour Doppler examination consisted of,

- Peak Systolic velocity of common carotid artery.

- Peak systolic velocity of internal carotid artery.

- Velocity ratios between internal carotid artery and common carotid arteries.

- Plaque characteristics as seen on the real time image.

- The presence of Spectral broadening.

All the examination was performed with a Doppler angle of 60 degrees.

\section{PROTOCOL FOR CAROTID DUPLEX EXAMINATION Longitudinal Survey}

Lateral transducer position,

- Begin at clavicle and move cephalad. Identify carotid bifurcation, ECA and ICA.

- Localize plaque and areas of obstruction to the CCA, ECA or ICA.
Posterolateral transducer position, Trace the ICA as far cephalad as possible searching for evidence of pathology.

\section{Longitudinal evaluation of Pathology}

Lateral or posterolateral transducer position,

- Document extent of plaque deposition.

- Document surface and internal characteristics of plaque.

- Measure peak-systolic and end-diastolic velocities and compare with proximal CCA velocities.

- Note degree of post stenotic flow disturbance.

Anterior transducer position Re-examine the entire carotid bifurcation to double check the findings made from a different perspective.

\section{TRANSVERSE EXAMINATION}

Begin at the clavicle and move cephalad.

Identify the carotid bifurcation, ECA, ICA. Localize plaque and areas of obstruction to the CCA, ECA or ICA. Document surface and internal characteristics of plaque. Measure residual lumen size and percent diameter reduction. Ascertain whether or not the B-mode measurements of stenosis correspond with the Doppler spectral measurements.

\section{IMAGING PROTOCOL}

MR angiography was performed on a GE 1.5-TESLA SIGNA HDXT 16 Channel MRI equipped with gradient overdrive with an ultrafast $120 \mathrm{mT}(\mathrm{m} \cdot \mathrm{msec})$ slew rate and high $33 \mathrm{mT} / \mathrm{m}$ peak amplitude whole-body gradient. A $4 \times 2$ circularly polarized phased array head and neck coil was placed around the neck. After obtaining classic fast spoiled gradient-echo axial, coronal, and sagittal localizers, 3D time-of-flight MR angiography and 3D gadolinium-enhanced MR angiography were successively performed. Because of better anatomic coverage, better spatial resolution in the slice thickness and the potential to use short TEs in our scanner (Which diminishes dramatically any artifacts caused by slow flows), 3D time-of-flight MR angiography was chosen for our study rather than 2D time-of-flight MR angiography. The multislab 3D time-of-flight technique comprised seven slabs, each with 32 axial sections, $1.41 \mathrm{~mm}$ thick with a superior saturation band, and imaging parameters of $39 / 7$ (TR/TE), one excitation, $25^{\circ}$ flip angle, $160 \times 256$ matrix size, and a $250 \times 250 \times 90 \mathrm{~mm}$ field of view. Examinations were centered on the carotid bifurcation, which could be visualized easily on the localizer.

Three-dimensional gadolinium-enhanced MR angiography was subsequently performed. Because the technique is not based on a flow entrance effect but on a T1 lowering of the blood (Compared with the surrounding tissues) by prescribing slabs in the coronal plane, it was possible to cover the region from the aortic arch to the carotid siphon. Turbo MR Angiography was a spoiled gradientrecalled echo sequence performed with a $1.5 \mathrm{msec}$ TR, a 1.0 msec TE, a $30^{\circ}$ flip angle, a $300 \times 225 \mathrm{~mm}$ field of view, a $320 \times$ 160 matrix, and 42 partitions each $2 \mathrm{~mm}$ thick with zero filling in the z-axis, which resulted in an imaging time of $4 \mathrm{sec}$. The $\mathrm{K}$-space was filled in sequential order. Fifteen milliliters of contrast medium was hand-injected at a rate between 2 and $3 \mathrm{~mL} / \mathrm{sec}$ into an antecubital vein at the beginning of the scan, followed by a $15-\mathrm{ml}$ saline flush. Five consecutive 3D sequences were performed ( 40 -sec total acquisition time). No 
breath-holding was used. No bolus test preceded the acquisition.

The contrast medium was gadopentetate dimeglumine. Acquisition time was 13 minutes. MR angiography studies were reviewed after post processing with a maximum-intensity projection algorithm with targeted maximum intensity projection used to display 13 projections of each carotid bifurcation separately $\left(14^{\circ}\right.$ angle $)$. For the $3 \mathrm{D}$ gadolinium enhanced studies, the maximum intensity projection algorithm was applied after subtracting sequence that showed the best arterial enhancement from the sequence showing no arterial enhancement (the mask). In cases of venous enhancement, subtraction was performed with the last sequence containing low arterial signal intensity and intermediate venous signal intensity.

\section{RESULTS}

The word stroke implies brain cell death caused by infarction resulting in deficit enduring for days or longer. The deficit may be fleeting, in which case the cell death presumably does not occur. Such a brief episode is termed as Transient Ischemic Attack (TIA). For epidemiological reasons, a neurological deficit lasting less than 24 hours is termed as TIA. A longer lasting deficit with full recovery within three weeks is termed as Reversible Ischemic Neurological Deficit (RIND). Treatment of stroke depends on reaching the most accurate possible diagnosis possible through clinical and laboratory evaluation (G. K. CALL 2000).

Two randomized clinical trials, the North American Symptomatic Carotid Endarterectomy Trial (NASCET) and European Carotid Surgery Trial (ECST) have clearly shown the benefit of Endarterectomy in symptomatic patients with greater than $70 \%$ carotid stenosis (C. RANKE 1999). The same reports showed lack of any benefit for surgery on lesions of $30 \%$ diameter. Another randomized trial-Asymptomatic carotid surgery trial showed distinct advantage for surgical intervention for patient who had at least $60 \%$ stenosis as quoted by Joseph F. Polak.

Angiography is the gold standard, but it is invasive and expensive and involves significant risk to the patients. Sonography is unique among vascular imaging procedures, in that it can assess plaque composition. Sonographically detected plaque characteristics may have prognostic value and may be useful for the selection of medical and surgical therapy. Our present study consists of evaluating extracranial carotid artery system in 50 patients with color Doppler and contrast enhanced Magnetic resonance Angiography in the population presented with stroke.

\section{DISCUSSION}

\section{Age and Sex Distribution}

Palomaki $\mathrm{H}$ et al. studied the risk factors for cervical atherosclerosis in patients with ischemic stroke and transient ischemic attack and found that incidence of stroke increases after 60 years of age. 4 The highest number of stroke patients in our study were found in the age group of 51- 60 and 61-70 years which was $34 \%$ that is 17 patients in 51-60 years and 17 patients in 61-70 years followed by $41-50$ years which was $18 \%$ [9 patients], >80years is $8 \%$ [ 4 patients] and $71-80 \%$ is $6 \%$ [3 patients]. [Table1] Lemolo $\mathrm{F}$ et al. in his study showed that only $2.5 \%$ of stroke victims were females. In this study $84 \%$ of the patients $(42 / 50)$ were males and $16 \%$ [8/50] of the patients were females. 43 [Table 2] Schulz U. G. R. Flossmann E and Rothwell studied family history of stroke and found that $23 \%$ of stroke patients had positive family history of stroke. ${ }^{5}$ in this study family history of stroke was present in 19 patients [38\%]. Table-3 shows the main presenting complaints and symptoms. Hemiparesis was seen in 20 patients [40\%] and family history of stroke in 19 patients [38\%] Grading of the stenosis was done according to the NASCET criteria. Table 4 shows comparison of the Doppler and MRA findings in the evaluation of the total pathologies. Doppler showed abnormalities in the Bulb in 7 patients [14\%], whereas in MRA it is 5 patients [10\%]. P value is $0.071+$.

Erickson SJ, Mewissen MW, et al. (1989) analyzed 49 patients with various Doppler velocity parameters for carotid artery stenosis and correlated with angiography. They found that B-mode measurement of diameter stenosis is most accurate at less than $40 \%$ diameter stenosis. In our study, Table 5 shows the comparison of the Doppler and MRA findings in evaluation of $16-49 \%$ stenosis. Doppler showed abnormalities in the Bulb in 3 patients [6\%], whereas in MRA it is 1 patient [2\%]. P value is 0.090 .

JM Serfaty, P Chirossel, JM Chevallier, et al. found that MRA is inaccurate in assessing $50-70 \%$ stenosis because of its false positives due to overestimation of the stenosis. ${ }^{6}$ In our study Table 6 shows comparison of the Doppler and MRA findings in evaluation of the 50-69\% stenosis. Doppler showed abnormalities in 3 patients [6\%], whereas in MRA it is 0 . $P$ value is $0.077+$. The difference was found to be statistically significant.

Paul J Nederkoorn, Yolanda Vander Graff, MG Myriam Hunink found that MRA has better discriminatory power compared with duplex ultrasonography in detecting 70-99\% stenosis. For detecting occlusion both MRA and ultrasound are accurate. ${ }^{7}$

In our study Table 7 shows comparison of the Doppler and MRA findings in evaluation of the $70-79 \%$ stenosis. Abnormal findings are equal on both Doppler and MRA. P value is 1 . Table 8 shows comparison of the Doppler and MRA findings in evaluation of the $80-99 \%$ stenosis. MRA showed abnormalities in 3 patients [6\%], whereas in the Doppler it is 0 . $P$ value is $0.077+$. The difference was found to be statistically significant. Table 9 shows comparison of the Doppler and MRA findings in the evaluation of the occlusion. Abnormal findings are equal on both Doppler and MRA. P value is 1. Observations in Table 8 and 9 are similar to the experience of Paul J Nederkoorn as stated above.

Table 10 shows comparison of the Doppler and MRA findings in evaluation of the morphology of the stenosis. Doppler showed abnormalities in 9 patients whereas in MRA it is 6 . P value is 0.283 . The difference was found to be statistically significant. This difference is MR Angiography is because of its relative insensitivity to arterial calcification. Aburahma Ali F, Wulu John T and Crotty Brad. Have confirmed that soft plaques and non-homogeneous plaques are more positively correlated with symptoms than with any degree of stenosis and were the cause of adverse neurological events.8,9

Out of 50 patients in this study 2 patients had soft plaques, 5 had non-homogenous plaques, 2 had calcified plaques and one patient was found to have ulcerative plaque. Table 11 shows comparison of the Doppler and MRA findings in evaluation of the thrombosis. 
Abnormal findings were equal on both Doppler and MRA. $P$ value is 1 . Table 12 shows comparison of the Doppler and MRA findings in evaluation of the collaterals. Abnormal findings were seen in 33 patients in MRA, none on Doppler.

$P$ value is $<0.001^{* *}$ suggests strongly significant. Table 13 shows comparison of the Doppler and MRA findings in evaluation of the location of the site.

Zwiebel J found that the carotid bifurcation was commonly involved by the atherosclerotic plaque followed by the origin of carotid. In our study also Bulb was found to be the commonest site affected by the plaque. In the Bulb plaque was identified in 7 patients followed by 2 patients in internal carotid artery. ${ }^{10}$

Table 14 shows total pathologies. On right side it is 32 patients in Doppler and 31 patients in MRA. On left side it is 19 patients in Doppler and 18 patients in MRA. On both sides it is 11 patients in Doppler and MRA.

\section{REFERENCES}

1. Caroli BA. Carotid Ultrasound. Neuroimaging clinics of North America. 1996;6:875-897.

2. Tahmasebpour HR, Buckley AR, Cooperberg PL: Sonographic examination of the carotid arteries. Radiographics. 2005;25:1561-1575.

3. Fontenelle Li, Simper SC, Hanson TL: carotid duplex scan versus angiography in evaluation of carotid artery disease. AJS. 1994;60:864-868.

4. Palomaki H, Kaste M, Raininko R, et al.: "Risk factors for cervical atherosclerosis in patients with transient ischemic attack or minor ischemic stroke:" Stroke 1993;24:970-975.

5. Lemolo F, Martiniuk A, Dteinman DA, et al.: "Sex differences in carotid plaque and stenosis:" Stroke 2004. Feb; 35(2):477-81.

6. Schulz UGR, Flossmann E, Rothwell P: "Heritability of ischemic stroke to age. Vascular risk factors and subtypes of incident stroke in population based studies:" Stroke 2004 Apr; 35(4):819-824.

7. Serfaty JM, Chirossel P, Chevallier JM, et al.: Accuracy of three dimensional gadolinium enhanced MR angiography in the assessment of the extracranial carotid artery disease: AJR 2000;175:455-463.

8. Paul J Nederkoorn, Yolanda Vander Graff, Myriam Hunink MG: Duplex ultrasound and magnetic resonance angiography compared with digital subtraction angiography in carotid artery stenosis: A Systematic Review: Stroke 2003;34:1324-1332.

9. Aburahma Au F, Wuiu John T, Crotty Brad: "Carotid plaque ultrasonic heterogeneity and severity of stenosis:" Stroke 2002;33:1772.

10. Zweibel William J: "Doppler evaluation of carotid stenosis" chapter 10 Introduction to vascular ultrasonography. $4^{\text {th }}$ edition. WB Saunders Company 2000;146-151.

\begin{tabular}{|c|c|c|}
\hline $\begin{array}{c}\text { Age in } \\
\text { Years }\end{array}$ & $\begin{array}{c}\text { No. of } \\
\text { Patients }\end{array}$ & $\mathbf{\%}$ \\
\hline $41-50$ & 9 & 18.0 \\
\hline $51-60$ & 17 & 34.0 \\
\hline $61-70$ & 17 & 34.0 \\
\hline $71-80$ & 3 & 6.0 \\
\hline$>80$ & 4 & 8.0 \\
\hline Total & $\mathbf{5 0}$ & $\mathbf{1 0 0 . 0}$ \\
\hline \multicolumn{3}{|c|}{ Table 1: Age distribution } \\
of patients studied \\
\hline
\end{tabular}

\begin{tabular}{|c|c|c|}
\hline Gender & $\begin{array}{c}\text { No. of } \\
\text { Patients }\end{array}$ & $\mathbf{\%}$ \\
\hline Female & 8 & 16.0 \\
\hline Male & 42 & 84.0 \\
\hline Total & $\mathbf{5 0}$ & $\mathbf{1 0 0 . 0}$ \\
\hline Table 2: Gender distribution of patients studied \\
\hline
\end{tabular}

\begin{tabular}{|c|c|c|}
\hline $\begin{array}{c}\text { Clinical } \\
\text { History }\end{array}$ & $\begin{array}{c}\text { No. of } \\
\text { Patients }\end{array}$ & $\mathbf{\%}$ \\
\hline Hemiparesis & 20 & 40.0 \\
\hline Stroke & 19 & 38.0 \\
\hline Weakness & 6 & 12.0 \\
\hline CVA & 4 & 8.0 \\
\hline $\begin{array}{c}\text { Diabetes } \\
\text { mellitus }\end{array}$ & 1 & 2.0 \\
\hline Total & $\mathbf{5 0}$ & $\mathbf{1 0 0 . 0}$ \\
\hline \multicolumn{3}{|c|}{ Table 3: Clinical History } \\
\hline
\end{tabular}

\begin{tabular}{|c|c|c|c|c|c|c|}
\hline \multirow{2}{*}{$\begin{array}{c}\text { TOTAL } \\
\text { PATHOLOGIES }\end{array}$} & $\begin{array}{c}\text { Total } \\
\text { Patients }\end{array}$ & \multicolumn{2}{|c|}{ DOPPLER } & \multicolumn{2}{|c|}{ MR } \\
ANGIOGRAPHY & \multirow{2}{*}{$\begin{array}{c}\text { P } \\
\text { VALUE }\end{array}$} \\
\cline { 3 - 6 } & & No. & $\%$ & No. & $\%$ & \\
\hline CCA & 50 & 1 & 2.0 & 1 & 2.0 & 1.000 \\
\hline BULB & 50 & 7 & 14.0 & 5 & 10.0 & $0.071+$ \\
\hline ECA & 50 & 0 & 0.0 & 0 & 0.0 & - \\
\hline ICA & 50 & 28 & 56.0 & 28 & 56.0 & 1.000 \\
\hline VERTEBRAL & 50 & 26 & 52.0 & 26 & 52.0 & 1.000 \\
\hline \multicolumn{7}{|c|}{ Angiography in detecting total pathology } \\
\hline
\end{tabular}

Paired Proportion test

\begin{tabular}{|c|c|c|c|c|c|c|}
\hline \multirow{2}{*}{$\begin{array}{c}\text { 50-69\% } \\
\text { STENOSIS }\end{array}$} & \multirow{2}{*}{$\begin{array}{c}\text { Total } \\
\text { Patients }\end{array}$} & \multicolumn{2}{|c|}{ DOPPLER } & \multicolumn{2}{c|}{$\begin{array}{c}\text { MR } \\
\text { ANGIOGRAPHY }\end{array}$} & \multirow{2}{*}{$\begin{array}{c}\text { P } \\
\text { VALUE }\end{array}$} \\
\cline { 3 - 6 } & & No. & $\%$ & No. & $\%$ & \\
\hline CCA & 50 & 0 & 0.0 & 0 & 0.0 & - \\
\hline BULB & 50 & 2 & 4.0 & 0 & 0.0 & $0.077+$ \\
\hline ECA & 50 & 0 & 0.0 & 0 & 0.0 & - \\
\hline ICA & 50 & 1 & 2.0 & 0 & 0.0 & 0.241 \\
\hline VERTEBRAL & 50 & 0 & 0.0 & 0 & 0.0 & - \\
\hline \multicolumn{7}{|c|}{ Table 6: Role of Doppler and MR } \\
Angiography in detecting pathology \\
\hline
\end{tabular}

Paired Proportion test

\begin{tabular}{|c|c|c|c|c|c|c|}
\hline 70-79\% & Total & \multicolumn{2}{|c|}{ DOPPLER } & \multicolumn{2}{|c|}{ MRANGIOGRAPHY } & P \\
\cline { 3 - 6 } STENOSIS & Patients & No. & \% & No. & \% & VALUE \\
\hline CCA & 50 & 0 & 0.0 & 0 & 0.0 & - \\
\hline BULB & 50 & 2 & 4.0 & 2 & 4.0 & 1.000 \\
\hline ECA & 50 & 0 & 0.0 & 0 & 0.0 & - \\
\hline ICA & 50 & 1 & 2.0 & 1 & 2.0 & 1.000 \\
\hline VERTEBRAL & 50 & 0 & 0.0 & 0 & 0.0 & - \\
\hline
\end{tabular}

Table 7: Role of Doppler and MR

Angiography in detecting pathology

Paired Proportion test

\begin{tabular}{|c|c|c|c|c|c|c|}
\hline \multirow{2}{*}{$\begin{array}{l}\text { 80-99\% } \\
\text { STENOSIS }\end{array}$} & \multirow{2}{*}{$\begin{array}{c}\text { Total } \\
\text { Patients }\end{array}$} & \multicolumn{2}{|c|}{ DOPPLER } & \multicolumn{2}{|c|}{$\begin{array}{c}\text { MR } \\
\text { ANGIOGRAPHY } \\
\end{array}$} & \multirow{2}{*}{$\begin{array}{c}\text { P } \\
\text { VALUE }\end{array}$} \\
\hline & & No. & $\%$ & No. & $\%$ & \\
\hline CCA & 50 & 0 & 0.0 & 0 & 0.0 & - \\
\hline BULB & 50 & 0 & 0.0 & 2 & 4.0 & $0.077+$ \\
\hline ECA & 50 & 0 & 0.0 & 0 & 0.0 & - \\
\hline ICA & 50 & 0 & 0.0 & 1 & 2.0 & 0.241 \\
\hline VERTEBRAL & 50 & 0 & 0.0 & 0 & 0.0 & - \\
\hline \multicolumn{7}{|c|}{$\begin{array}{l}\text { Table 8: Role of Doppler and MR } \\
\text { Angiography in detecting pathology }\end{array}$} \\
\hline
\end{tabular}

Paired Proportion test 


\begin{tabular}{|c|c|c|c|c|c|c|}
\hline \multirow{2}{*}{$\begin{array}{c}\text { COMPLETE } \\
\text { OCCULSION }\end{array}$} & \multirow{2}{*}{$\begin{array}{c}\text { Total } \\
\text { Patients }\end{array}$} & \multicolumn{2}{|c|}{ DOPPLER } & \multicolumn{2}{|c|}{ MR } & \multirow{2}{*}{$\begin{array}{c}\text { P } \\
\text { ANGIOGRAPHY }\end{array}$} \\
\cline { 3 - 6 } & & No. & $\mathbf{\%}$ & No. & \% & \\
\hline CCA & 50 & 1 & 2.0 & 1 & 2.0 & 1.000 \\
\hline BULB & 50 & 0 & 0.0 & 0 & 0.0 & - \\
\hline ECA & 50 & 0 & 0.0 & 0 & 0.0 & - \\
\hline ICA & 50 & 26 & 52.0 & 26 & 52.0 & 1.000 \\
\hline VERTEBRAL & 50 & 26 & 52.0 & 26 & 52.0 & 1.000 \\
\hline
\end{tabular}

Table 9: Role of Doppler and MR Angiography in detecting pathology

Paired Proportion test

\begin{tabular}{|c|c|c|c|c|c|c|}
\hline $\begin{array}{c}\text { MORPHOLOGY } \\
\text { OF } \\
\text { STENOSIS }\end{array}$ & \multirow{2}{*}{$\begin{array}{c}\text { Total } \\
\text { Patients }\end{array}$} & \multicolumn{2}{|c|}{ DOPPLER } & \multicolumn{2}{|c|}{ MR } & \multirow{2}{*}{ ANGIOGRAPHY } \\
\cline { 3 - 6 } & & No. & $\%$ & No. & $\%$ & VALUE \\
\hline CCA & 50 & 0 & 0.0 & 0 & 0.0 & - \\
\hline BULB & 50 & 7 & 14.0 & 5 & 10.0 & 0.283 \\
\hline ECA & 50 & 0 & 0.0 & 0 & 0.0 & - \\
\hline ICA & 50 & 2 & 4.0 & 1 & 2.0 & 1.000 \\
\hline VERTEBRAL & 50 & 0 & 0.0 & 0 & 0.0 & - \\
\hline \multicolumn{7}{|c|}{ Table 10: Role of Doppler and MR } \\
\hline
\end{tabular}

Paired Proportion test

\begin{tabular}{|c|c|c|c|c|c|c|}
\hline \multirow{2}{*}{ THROMBOSIS } & \multirow{2}{*}{$\begin{array}{c}\text { Total } \\
\text { Patients }\end{array}$} & \multicolumn{2}{|c|}{ DOPPLER } & \multicolumn{2}{c|}{ MR } \\
ANGIOGRAPY & \multirow{2}{*}{ P VALUE } \\
\cline { 3 - 7 } & & No. & $\mathbf{\%}$ & No. & $\%$ & \\
\hline CCA & 50 & 1 & 2.0 & 1 & 2.0 & 1.000 \\
\hline BULB & 50 & 0 & 0.0 & 0 & 0.0 & - \\
\hline ECA & 50 & 0 & 0.0 & 0 & 0.0 & - \\
\hline ICA & 50 & 26 & 52.0 & 26 & 52.0 & 1.000 \\
\hline VERTEBRAL & 50 & 26 & 52.0 & 26 & 52.0 & 1.000 \\
\hline \multicolumn{7}{|c|}{$\begin{array}{c}\text { Table 11: Role of Doppler and MR } \\
\text { Angiography in detecting pathology }\end{array}$} \\
\hline
\end{tabular}

Paired Proportion test

\begin{tabular}{|c|c|c|c|c|c|c|}
\hline \multirow{2}{*}{$\begin{array}{l}\text { COLLAT } \\
\text {-ERALS }\end{array}$} & \multirow{2}{*}{$\begin{array}{c}\text { Total } \\
\text { Patients }\end{array}$} & \multicolumn{2}{|c|}{ DOPPLER } & \multicolumn{2}{|c|}{$\begin{array}{c}\text { MR } \\
\text { ANGIOGRAPHY }\end{array}$} & \multirow[t]{2}{*}{ P VALUE } \\
\hline & & No & $\%$ & No & $\%$ & \\
\hline CCA & 50 & 0 & 0.0 & 1 & 2.0 & 0.241 \\
\hline BULB & 50 & 0 & 0.0 & 0 & 0.0 & 0.0 \\
\hline ECA & 50 & 0 & 0.0 & 0 & 0.0 & 0.0 \\
\hline ICA & 50 & 0 & 0.0 & 15 & 30.0 & $<0.001^{* *}$ \\
\hline $\begin{array}{l}\text { VERTEB } \\
\text { RAL }\end{array}$ & 50 & 0 & 0.0 & 17 & 34.0 & $<0.001^{* *}$ \\
\hline & $\begin{array}{r}\text { To } \\
\text { Ang }\end{array}$ & & $f$ & & & \\
\hline
\end{tabular}

Paired Proportion test

\begin{tabular}{|c|c|c|c|c|c|c|}
\hline \multirow{2}{*}{$\begin{array}{c}\text { LOCATION } \\
\text { OF STENOSIS }\end{array}$} & \multirow{2}{*}{$\begin{array}{c}\text { Total } \\
\text { Patients }\end{array}$} & \multicolumn{2}{|c|}{ DOPPLER } & \multicolumn{2}{c|}{ MR } & \multirow{2}{*}{ P } \\
& & & ANGIOGRAPH & VALUE \\
\hline & & No & $\%$ & No & $\%$ & \\
\hline CCA & 50 & 0 & 0.0 & 0 & 0.0 & - \\
\hline BULB & 50 & 7 & 14.0 & 7 & 14.0 & 1.000 \\
\hline ECA & 50 & 0 & 0.0 & 0 & 0.0 & - \\
\hline ICA & 50 & 2 & 4.0 & 2 & 4.0 & 1.000 \\
\hline VERTEBRAL & 50 & 0 & 0.0 & 0 & 0.0 & - \\
\hline \multicolumn{6}{|c|}{$\begin{array}{c}\text { Table 13: Role of Doppler and MR } \\
\text { Angiography in detecting pathology }\end{array}$} \\
\hline
\end{tabular}

Paired Proportion test

\begin{tabular}{|c|c|c|c|c|c|c|c|}
\hline AFFECTED SIDE & & \multicolumn{3}{|c|}{ DOPPLER } & \multicolumn{2}{|c|}{ MR ANGIOGRAPHY } \\
\cline { 3 - 8 } $\begin{array}{c}\text { TOTAL PATHOLOGIES } \\
\text { STENOSIS+ } \\
\text { OCCULSION }\end{array}$ & $\begin{array}{c}\text { Total No. of } \\
\text { Patients }\end{array}$ & BOTH & RIGHT & LEFT & BOTH & \multirow{2}{*}{ RIGHT } & LEFT \\
\hline CCA & 50 & 0 & 0 & $1(2.0 \%)$ & 0 & 0 & $1(2.0 \%)$ \\
\hline BULB & 50 & $1(2.0 \%)$ & $4(8.0 \%)$ & $2(4.0 \%)$ & $1(2.0 \%)$ & $3(6.0 \%)$ & $1(2.0 \%)$ \\
\hline ECA & 50 & 0 & 0 & 0 & 0 & 0 & 0 \\
\hline ICA & 50 & $3(6.0 \%)$ & $16(32.0 \%)$ & $9(18.0 \%)$ & $3(6.0 \%)$ & $16(32.0 \%)$ & $9(18.0 \%)$ \\
\hline VERTEBRAL & 50 & $7(14.0 \%)$ & $12(24.0 \%)$ & $7(14.0 \%)$ & $7(14.0 \%)$ & $12(24.0 \%)$ & $7(14.0 \%)$ \\
\hline \multicolumn{7}{|c|}{ Table 14: Role of Doppler and MR Angiography in detecting pathology } \\
\hline
\end{tabular}

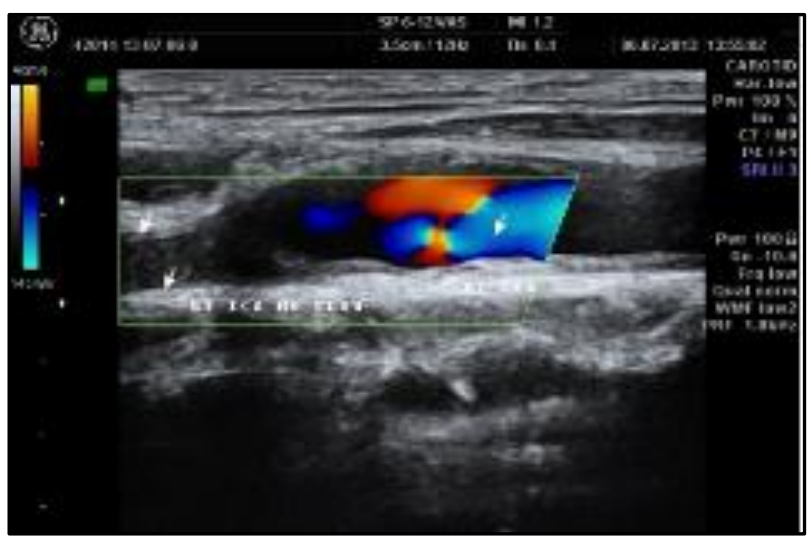

Fig.1: Longitudinal US image with thrombus in right ICA showing no flow on colour Doppler

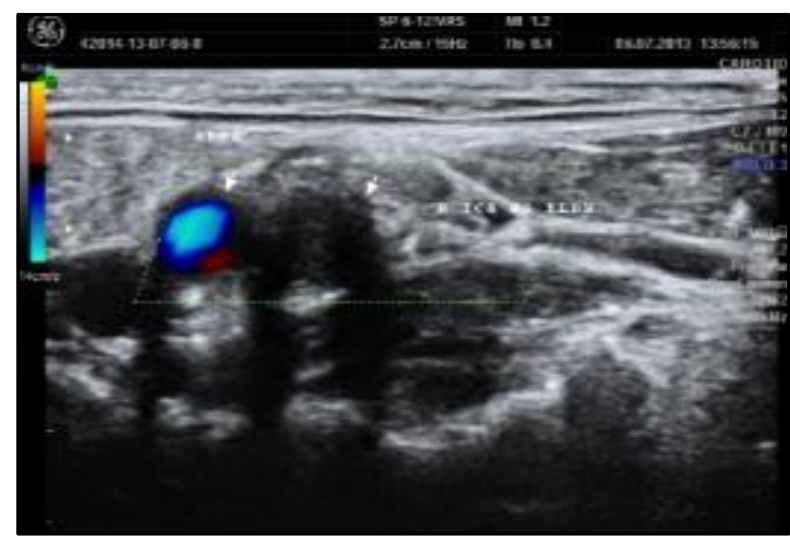

Fig. 2: Transverse US image with thrombus in right ICA showing no flow on colour Doppler 


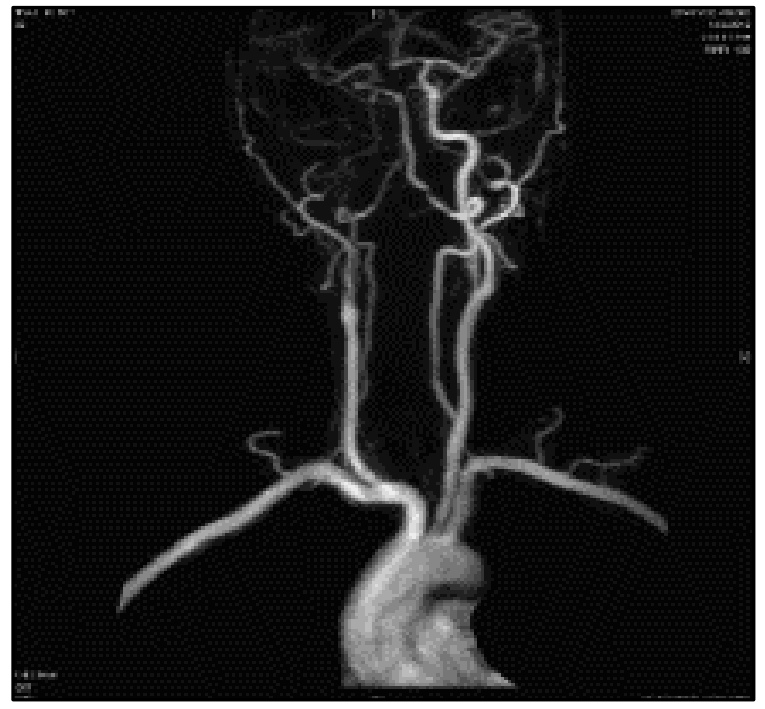

Fig. 3: Complete Occlusion of Right ICA on MRA
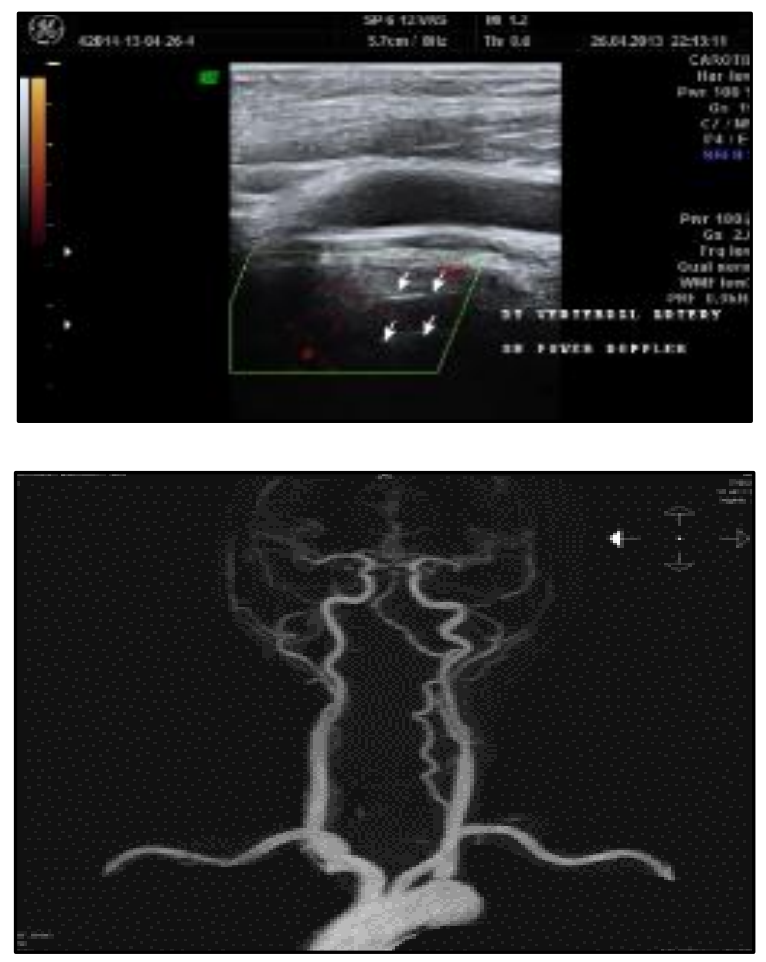

Fig. 4: Right vertebral artery showing no flow on power Doppler and MRA

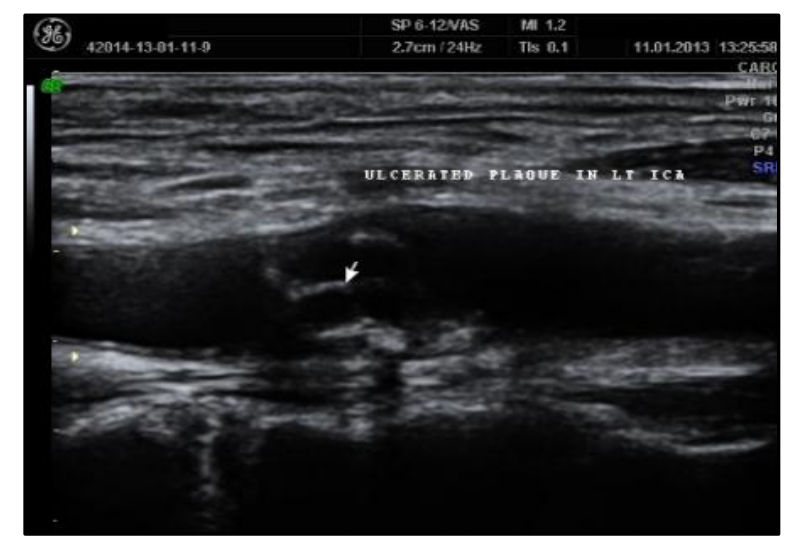

Fig. 5: Longitudinal US image showing ulcerated plaque

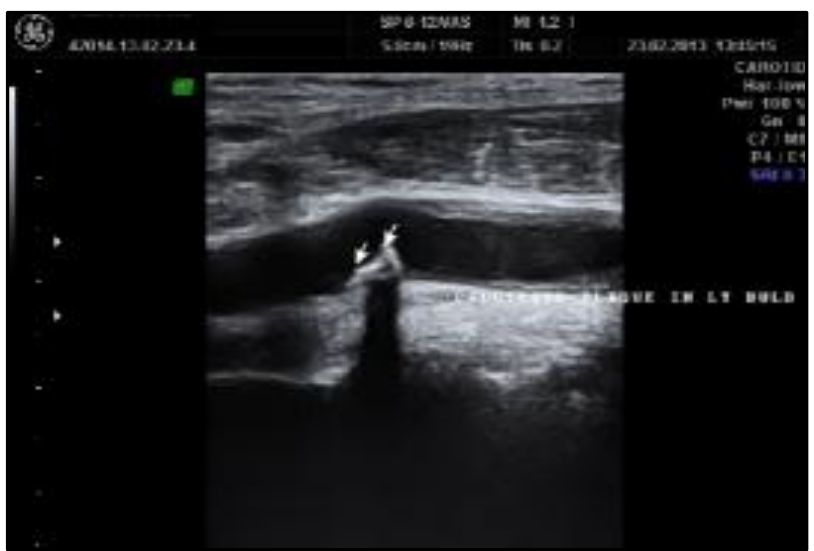

Fig. 6: Longitudinal US image showing calcified plaque in left bulb causing posterior acoustic shadowing

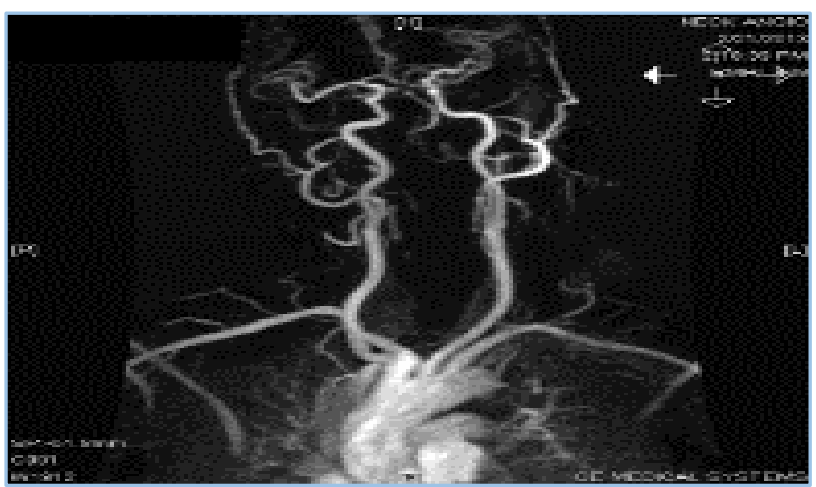

Fig. 7: Complete occlusion of Bilateral Vertebral Arteries on MRA

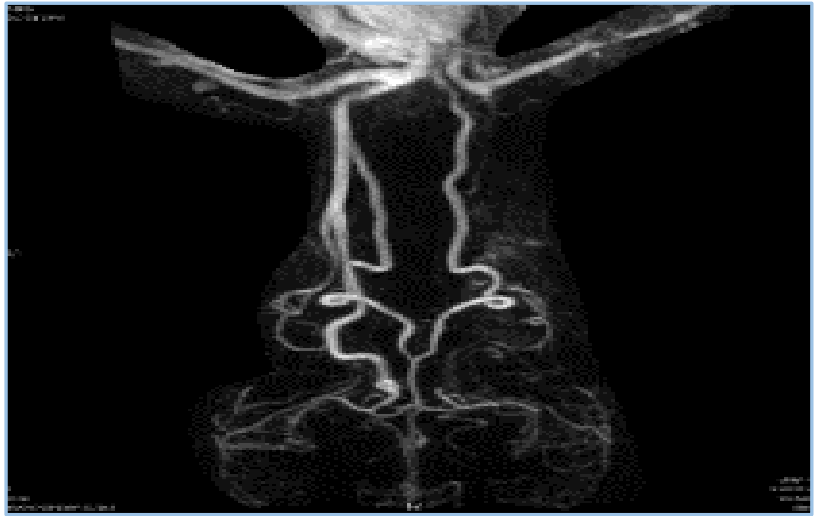

Fig. 8: Complete occlusion of left common carotid artery from its origin on MRA

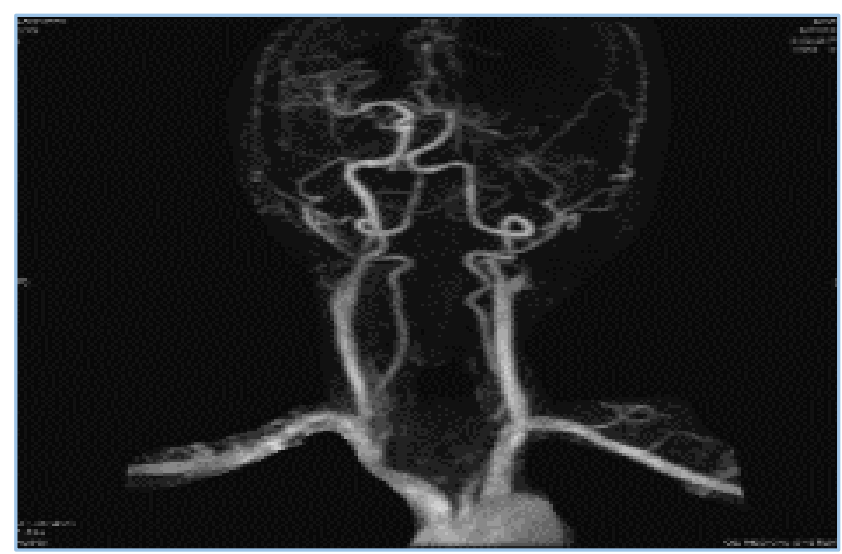

Fig. 9: Complete occlusion of left ICA on MRA 


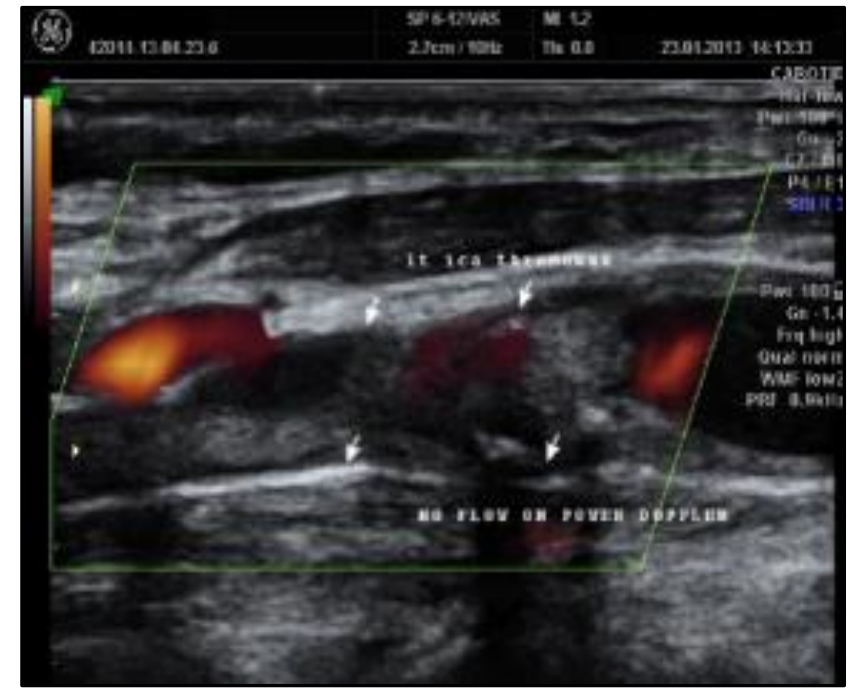

Fig. 10: Left ICA thrombus showing no flow on power Doppler

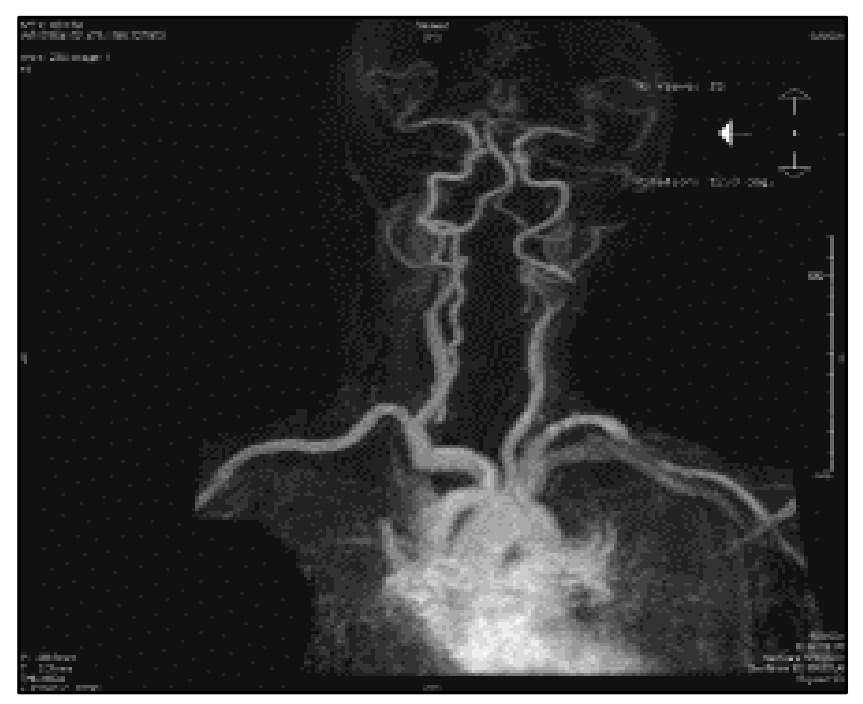

Fig. 11: MRA showing occlusion of bilateral vertebral vertebral arteries at origin from subclavian artery but reformatted by collaterals distally

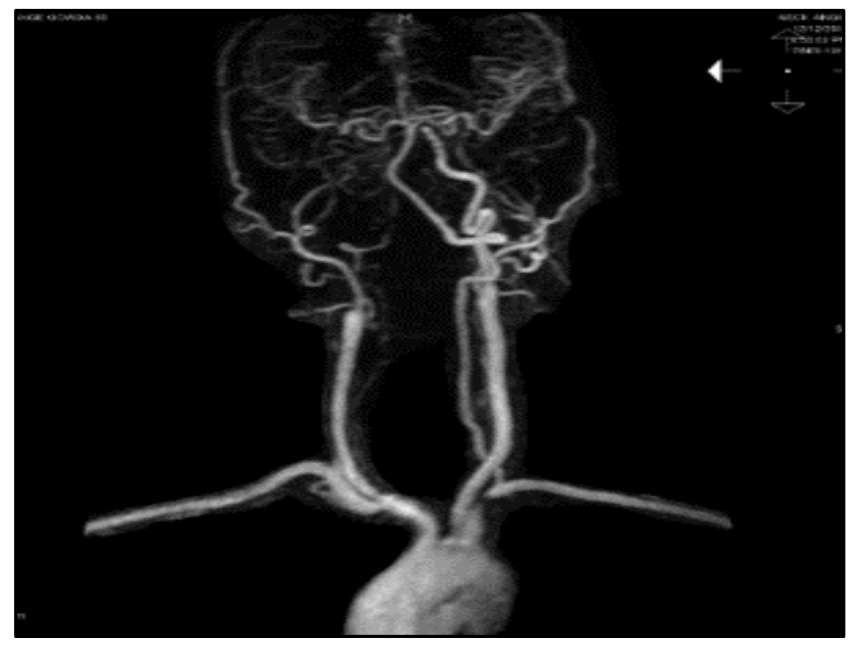

Fig. 12: Complete occlusion of Right ICA and Vertebral Artery on MRA 